\title{
Conceptual aspects of modern innovation policy
}

\author{
Vitaliy Omelyanenko ${ }^{1}$, Olga Kudrina*2, Olena Semenikhina ${ }^{3}$, Vasily Zihunov ${ }^{4}$, \\ Olena Danilova ${ }^{5}$, Tetiana Liskovetska ${ }^{6}$
}

\begin{abstract}
The country's participation in the processes of high technology development and transfer depends on: the level of its socio-economic development; the effectiveness of identifying innovative priorities; the developing an international strategy. This necessitates the development of theoretical foundations and practical recommendations for countries' participation in high technology development processes in the global innovation system.

We propose to consider high technology analysis as an analysis of public policy (interpretive analytics) and research in science and technology and technology assessment.

Recently, an approach has come to the fore, in which it is necessary to focus not so much on absolute leaders who have already built their own chain of creation of innovations (from basic research to competitive companies), but more to develop their own unique competencies.

The factor of formation of competitive innovative systems is creation of unique innovative environment on the basis of combination of technological basis, innovative economy and sociocultural system.
\end{abstract}

Keywords: innovation policy, high technology, innovative landscapes, clusters, buman resources, technology transfer.

\section{Introduction}

Development of high technologies and their spread between countries is an integral part of the global economic process, and the effectiveness of national innovation systems is increasingly evaluated based on the use of developed technologies in the world market. The country's involvement in the processes of high technology development and transfer depends on the level of its socio-economic development and the effectiveness of defining innovative priorities and developing an international strategy. This necessitates the development of theoretical foundations and practical recommendations for countries' participation in high technology development processes in the global innovation system.

The analysis of high technology and its international transfer will be viewed as part of a wider field - interpretive policy analysis and the science and technology research evaluation.

| ${ }^{1} \mathrm{PhD}$ (Economic Sciences), Associate Professor, Department of Business Economics and Administration, Makarenko Sumy State Pedagogical University, Ukraine.

${ }^{2}$ D. Sc. (Economic Sciences), Professor, Head of Business Economics and Administration Department, Makarenko Sumy State Pedagogical University, Ukraine. *Corresponding Author.

${ }^{3}$ D. Sc. (Pedagogical Science), Professor, Head of Informatics Department, Makarenko Sumy State Pedagogical University, Ukraine.

${ }^{4} \mathrm{PhD}$ (Pedagogical Science), Associate Professor, Department of Tourism and Hotel-Restaurant Service, Makarenko Sumy State Pedagogical University, Ukraine.

${ }^{5} \mathrm{PhD}$ (Economic Sciences), Senior Lecturer in the Department of Management and Administration, Melitopol Bohdan Khmelnitsky State Pedagogical University, Ukraine.

${ }^{6} \mathrm{PhD}$ (Economic Sciences), Associate Professor of the Department of International Relations, Kyiv National University of Culture and Arts, Ukraine. 
The potential benefits of high technologies are significant, but they require the attention of the state and significant investments that together shape the conditions for their implementation and development. If the state waits to realize the potential of technology to influence the technology economy, it will be too late to reap the benefits and benefits or to respond appropriately to the consequences. Thus, countries can rise to a new level and lose positions (Antoniuk, Poruchnik, \& Savchuk, 2003).

\section{Theoretical bases of successful technology transfer}

OECD experts identify the main trends in the formation of conditions for successful technology transfer (IEA, 2010):

- innovation is increasingly dependent on the interaction between science and business;

- competitive markets and the accelerating pace of scientific and technological change are forcing more innovative technologies;

- cooperation between companies is playing an increasingly important role today and is increasingly involving high-tech services;

- small and medium-sized enterprises, especially new technology firms, play a greater role in technology development and transfer;

- the interdependence of innovative systems is increasing in the context of globalization. Recently, an approach has come to the fore, according to which it is necessary to focus not so much on absolute leaders, who have already built their own chain of creating innovation from basic research to competitive companies, but more on the development of own unique competencies.

This conclusion is also contained in the report (Global Innovation Index, 2013), which emphasizes on the conditions of development of innovations at the local level, which remain undervalued on a global scale, and notes the emergence of original innovative ecosystems and the need to move away from the trend of reproduction of already successful initiatives, which were realized earlier. On this basis, we believe that research into ecosystems of innovation should be continued.

\section{Technological factor of economic development: theoretical framework}

Technological progress is already changing the structure of the economy. In recent years, we can observe at the same time three parallel and interconnected scientific and technological revolutions and a new fourth, the development of which determines the extreme nature of the buildout of STP:

1. The revolution in information technology began earlier than others, and its current stage is related to the development and implementation in all areas of telecommunications and information networks. According to official figures, spending on computer hardware and software rose from 18.2\% of total business expenses in 1987 to a peak of $46.7 \%$ at the end of 2000 . After that, a long and steady decline began. It is now apparent that autonomous IT is no longer a priority for most companies, as in the 1990s.

2. The revolution in biomedical sciences and technologies began in the late twentieth century. with the development of cellular and molecular biology; major achievements 
include mapping the human and other species genome, cloning and more. Now the amount of knowledge about biology is doubling every 3 years. The first practically significant fruits of this revolution are just beginning to enter our lives;

3. The revolution in nanotechnology involves the ability to manipulate matter at the molecular and atomic levels. In this area, progress is at an early stage, but there are new developments every year and significant results are expected in the coming years;

4. The revolution in the cognitive sciences is based on the fact that the knowledge of how the human brain works is rather limited. However, with the emergence of new methods of research, such as MEG, PET and fMRi, opportunities are increasing.

After 2000, many economists began to consider technology shocks caused by investment activity (investment-specific technological change) as a source of business cycles. In conventional RBC models, the standard technology shock causes work productivity and capital productivity to grow. Under the conditions of investment and technology shock, the productivity of available fixed capital does not change, but the return on investment increases.

In monetary RBC models, technology shocks are often the source of business cycles, but monetary factors are actively involved in shaping the economic response to technology shocks. Appropriate monetary policy is required for technology shock to have a significant impact on economic growth in the short term.

For a more detailed analysis of the ratio of innovation-investment processes and employment of the population in modern conditions, it is advisable to analyze the main approaches to explaining the current situation:

- the cyclical explanation, supported by P. Krugman, shows that there is nothing new in what is happening, and that the world economy is going through one of the cycles of development. The economy is growing at a rather slow pace, so with recessions like the 2007-2009 recession there will be a long-term recovery;

- the concept of economic stagnation, according to which, for example, the United States has entered the technological plateau and can no longer offer innovations that would increase productivity and sustain the economy. New ideas are being implemented too slowly and the United States is unable to compete internationally;

- J. Rifkin's "end-of-work" theory suggests that technological progress is evolving too quickly, not too slowly. The researcher notes that there is a transition to a new phase in history, in which fewer resources are needed to produce goods and services needed by the global population.

Based on South Korea's quarterly data for 1985-2001, the impact of technological shocks on employment and productivity in the economy has been demonstrated: technological advances have ensured the long-term economic growth of this "Asian tiger", but negatively impacted employment in the short-run. In other words, the emergence of new technologies initially led to increased unemployment, and only then to the creation of additional jobs. This dependency is currently valid for many emerging economies. Before that, Western economists came to similar conclusions, studying the macro-level response of developed markets.

The existence of investment-specific technological change can be confirmed by the difference between the prices of investment and consumer goods. Over the past 40 years, the relative value of investment goods has dropped significantly. Investment- 
specific technological change account for more than $60 \%$ of the growth in post-war output in man - hour. According to other sources, investment and technological shock accounts for up to $50 \%$ of changes in time spent and $40 \%$ of changes in output. Ordinary technology shocks account for less than $10 \%$ of the change in these variables (Fisher, 2003).

The main assumptions of the real business cycle model are that:

- technological changes are an important source of economic shocks;

- perfect competition type of market structure serves as an environment for spreading technology shocks.

An additional source of business cycles are also news shocks (Benko, \& Schrogl, 2005). There is a situation where agents learn about new promising technology that will necessarily affect the performance of factors in the future. The question arises as to whether current productivity will increase and whether a recession will occur if the effect of the technology turns out to be less than expected (Rebelo, 2010).

In this context, the main assumption of the real business cycle model is that technology shocks can be both positive and negative, meaning, there is an opportunity for both technological progress and regression. According to this theory, it is the negative shocks that cause the recession. This view is supported by V. Polterovich (2008), who notes that the 2008 global crisis was caused by the transition to a new way.

As a result of the generalization and development of the model of technological gap, a model of the production cycle of Vernon V. appeared (Vernon, 1966). The scientist also identified the reasons why innovations are better implemented in developed countries:

1) developed countries have better technology deployment conditions that provide temporary benefits;

2) innovation development requires the closest possible approach to the market in order to use the benefits of communication with consumers when developing innovation;

3) country data can provide after-sales service.

In the model of technological gap, the invention of goods is considered the main aspect, in the model of life cycle - its standardization.

An example of production cycle theory is the production of radios in West Germany and the United States in the postwar period. In the international market, after the Second World War, radios were dominated by companies that used US-developed vacuum lamps. However, a few years later, Japan, by copying technology and using cheap labor, captured most of this market.

Technology shocks play a very important role for the developing economy because the country's relative technological backwardness requires more changes in the production process. This is especially true for catching-up countries importing overseas technologies that are central to a rapid industrial and economic spurt.

The growing openness of national economies creates the prerequisites for accelerated international diffusion of advanced technologies, know-how, management and marketing skills, and ultimately for the spread across the globe of the economic civilization that emerged in the industrial countries of the early XI century. This indicates that the gap in the levels of technical and economic development between the industrial or postindustrial segment of the world community and other countries will be narrowed. Judging by the GDP per capita, the tendency to narrow the gap has already been 
reflected at the turn of the 1960s and 1970s. However, the "pulling" of different groups of developing countries to the level of development of the avant-garde is uneven (The world at the turn of the millennium, 2001), as there are both global integration and cooperation trends in the scientific and industrial sphere, competition trends, competitive aspects of research, transfer and diffusion processes (Glushak, 2011).

Despite this, high consumer technologies have significant transfer potential. Evidence of this is the phenomenon of so-called technology leapfrogging, which is most clearly manifested in the transfer of ICTs when developing countries that have never had functional infrastructures adopt mobile and Internet technologies, which allow these countries to develop much faster than developed countries did for the first time.

Initial provisions of the theory of innovation were formulated by N.D. Kondratiev, which connected the waves of inventions and innovations with the transition to a new cycle. He found that "before the beginning of a wave of a large cycle, and sometimes at the very beginning, there are significant changes in the economic system, which are reflected in profound changes in technology of production and exchange (which in turn are preceded by significant technological inventions and discoveries)" (Kondratiev, 2002).

Changes in the field of production technology (technological innovations) imply two necessary conditions:

1) the availability of relevant scientific and technological discoveries and inventions

2) economic opportunities for the use of these discoveries and inventions.

The results of intellectual activity have considerable scientific and technical novelty and market value, which should be taken into account when managing the processes of creating revolutionary innovations.

In the context of new technology analysis, the term "technology convergence" or "convergent technology" is used in the scientific literature to mean a wide range of processes - the convergence of individual sciences or the convergence of technology itself. It should be noted that two points of view on the essence of the convergence process are expressed:

- simple interdisciplinary convergence based on the horizontal impact of technology on other technologies;

- the emergence of radically new areas of science and technology that will evolve in the future along their own trajectories (Towards a European Strategy for Nanotechnology, 2014).

In today's environment, there are major changes in the high-tech industries of many countries. The dynamics of technology recovery is increasing, the search for and development of competitive macro-technologies of the 21 st century is underway creation of funds on the basis of new principles, materials and components and miniaturization. Appendix B lists the types of future technologies that are available in the world's leading think tanks.

Modern high technologies are inter-sectoral technologies that have the potential to form the prerequisites for the development of a number of technological fields and areas of research and development, which in the aggregate make a significant contribution to solving key problems in the implementation of priority areas for the development of science and technology. 


\section{Research of conditions and contents of international cooperation spheres in the field of innovation}

Analysis of a number of studies has shown that the issue of international technology transfer is hardly considered as a criterion for evaluating national innovation systems. We also consider that the analysis should take into account the fact that progress in the development of high technology depends on the research and development of technology at the enterprise level on the one hand, and on the other - on the institutional development, i.e. the overall climate of creating new innovative companies, reducing the bar ' to promote the dynamic expansion of existing innovative enterprises and opportunities for realizing innovative potential.

In analyzing the international transfer of high technology as a specific type of international economic relations, it is necessary to take into account the general factors of development of the world economy, namely (Filipenko, 2013):

- the number of countries and the orientation of their national interests within the international division of labor;

- voluntary reconciliation of positions, which becomes more complex and less likely as the number of countries participating in the discussion grows and the less the expected contribution of each country to the results of international integration;

- world economic initiatives of individual countries, if the expected politically motivated economic gain of participation in the international division of labor is expected to be higher than the costs of their implementation;

- the desire of individual states to gain an advantage over others by violating existing rules (trade and organizational restrictions, currency manipulation, etc.);

- the possibility of using the individual leading states of their own legal rules to provide additional benefits;

- the continued existence of the system through legal discipline and the presence of a dominant state and its willingness, independently or through cooperation with other countries, to create incentives for the functioning of the world economic order and thus to reach consensus for the benefits of each subject (Prigulnyi, 2010).

Analyzing the tendencies of the development of the global innovation system, the following main features of its modern model are identified.

- formation of a single world scientific and technical space and market for high-tech goods and services;

- consolidation of certain specialization in the market of high-tech products for individual countries;

- formation of technological rent mechanisms within the framework of globalization, which forms the specialization of individual countries;

- formation of national innovation systems, that are integrated at the international level, cover the full range of institutions, providing innovation, development and transfer of technologies, which is a leading element of consolidation of the country's specialization in the world markets of high-tech products and support the technological interdependence of the national economy.

Accordingly, the goal of international transfer is to integrate into the global innovation landscape, and the key task of management is to create a unique innovation environment 
as a result of the combination of technological process, innovation economy and sociocultural system.

The impact of these elements should be considered based on the fact that innovation policy is implemented at three main levels: national, regional and local, the systematic and coordinated interaction of which, in a knowledge economy, affects economic growth.

Fig. 1 shows schematically the factorial groups that influence the processes of international cooperation.

\section{International organizations, TNC}

(Global innovation system)

(development of international policy provisions in the field of international

\section{Country}

(National innovation system)

(development of normative base of economic and innovation activity, choice of

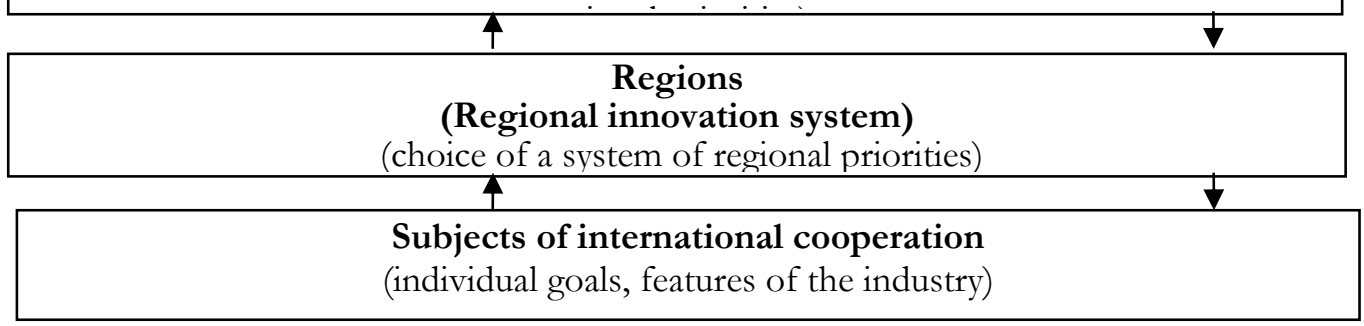

Fig. 1. Scheme of spheres of international cooperation in the innovation sphere.

Source: Developed by the author

At the same time, the policy on international technology transfer should, in our opinion, take into account global and national trends on the principle of selection in accordance with the chosen strategy (Fig. 2).

The sustainability of national innovation landscapes is a major asset in the formation of innovative systems and socio-economic development. In this regard, innovative landscapes are the focus of attention of researchers and practitioners (Prokopenko et al., 2019; Omelyanenko, Volodin, 2017).

The innovation landscape is a territory with different levels and nature of interaction and interdependence of the results of the innovation process at its various stages. The innovative landscape should be geared to sustainable development and reflect the specific socio-economic development of the territory. 
Based on this, a particular country (region) may choose to develop shared technologies (such as nanotechnology). In other regions, they may be refined and used in the production of specific products. Third, the focus should be on the development of creative industries.

Global tendencies (GT)

Regional innovation policy (RI)

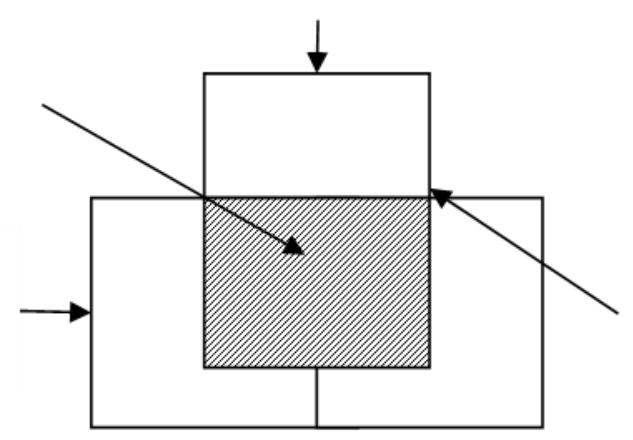

National innovation policy

Socio-economic situation in the region (RES)

$$
\begin{gathered}
\mathrm{RI}=\{(\mathrm{GT}, \mathrm{NP}, \mathrm{RES}) \in \mathrm{RI} \mid \mathrm{RI}(\mathrm{GT}, \mathrm{NP}, \mathrm{RES}) \\
\mathrm{RES}(\mathrm{t})=\mathrm{RES}(\mathrm{t}-1)+\alpha \cdot \mathrm{RI}(\mathrm{RES}(\mathrm{t}-1)) \\
a-\text { the weighting factor of the transition between iterations } t-1 \text { and } t \\
\text { (efficiency ratio of } \mathrm{RI})
\end{gathered}
$$

Fig. 2. The scheme of definition of innovation policy. Source: Developed by the author

On this basis, three types of innovative landscape are identified (Achkasova, \& Gorkin): - creative landscape, for example, "silicone" landscapes (Silicon Valley, Silicon Prairie, Silicone Forest, etc.);

- production innovation landscape - first wave NIC countries;

- landscape with pronounced consumption of innovative activity results - highly developed economic centers and regions.

The analysis of tendencies of development of national scientific and technical systems in the context of global system allows to distinguish three main models of innovative development and technology transfer (Krasnonosova, \& Oliinyk, 2011):

1) development of fundamental science: development of key technologies (materials science, nanotechnology, biotechnology);

2) expansion of high technology from developed countries or technological intervention: expansion of foreign capital in the form of high technology;

3) technology transfer through the acquisition of patents or licenses:

In the framework of the OECD (Managing National Systems of Innovation, 1999), the following leading aspects of organizational and economic forms of managing technological advancement are used to evaluate the effectiveness of technology transfer: 1. Innovative Enterprises (Canada, France, USA) - defining the characteristics of innovative firms in order to determine the impact of public policy on their number and effectiveness. In leading countries, such as the United States, the private sector accounts for up to $75 \%$ of R\&D costs, and these countries' top 100 international corporations have $90 \%$ of this sum; 
2. Innovation Networks (Denmark) - International communication networks, both at the individual and organizational levels, play a crucial role in the international development of the firm.

For example, the "Nano2Life», European network of centers of excellence in Nano biotechnology, created under the VI Framework Program to further transform into a virtual European Nanotechnology Institute, brings together more than 200 researchers from 23 research centers in 12 countries, including 5 centers in Canada, USA, South Korea and Australia, as well as about 30 associate partners - industry and universities. It has organized more than 40 consortia to develop joint projects with biotechnology companies (35\%), instrumentation (32\%), micro- and nanotechnology (both 14\% respectively) and computer technology (5\%) (European Landmark in nanobiotechnology, 2014).

3. Cluster structures (Netherlands) - research of innovation activity and technology transfer within clusters;

4. Human Resource Mobility (Norway, Sweden and EU) - features of the impact of human resource mobility on knowledge transfer in innovative systems;

5. Organizational reflection (Belgium) - analysis and comparison of institutional sets (profiles) of national innovation systems, as well as quantitative comparison of international networks of research cooperation;

6. Catch-up development toolkit (South Korea, PRC) - analysis of national innovation systems in "catch-up" type economies (creation of basic scientific and technological level and innovation infrastructure).

At the same time, the leading role of institutions should be emphasized: the formal establishment of institutions aimed at supporting innovation and technology transfer in conditions (1) - (5) cannot give effect - such institutions are doomed to dysfunction.

In the last 20 years, researchers and statesmen have been paying increasing attention to the problems of the formation of national innovation systems (NIS), which allow to obtain a synergistic effect of the development of institutions. The founder of the concept, K. Freeman, has identified NIS as a network of public and private sector institutions that interact, initiate, import, modify, and disseminate new technologies.

Therefore, we believe that countries seeking to integrate into the world transfer system should modify the existing institutional framework for technological exchange on the basis of consistent consideration of national interests and the interests of the subjects themselves.

The regulation of relations and institutions in the field of international technology transfer has recently developed. In the 1950's technology transfer activities were largely regarded as a supplement to the supply of goods. However, over the decades, the situation has changed dramatically: the intellectual component (the value of intellectual property and knowledge) in the price of goods has increased on average from $20 \%$ to almost $70 \%$. Increasing the value of technology and knowledge determines the dynamic development of legal regulation of relations in this field and the dynamics of institutions regulating these processes.

Institutes necessary for the effective development of international technology transfer can be grouped into the following groups: legal (protection of intellectual property rights in the territory of foreign countries), financial (investment security, insurance, crediting, 
improving the efficiency of financial payments), international (international organizations, regulating the issues of international technology exchange), innovative (system of improvement of existing technologies and their subsequent transfer), information (information support of legal, institutional, innovative areas).

The institutional development of innovation structures is influenced by the interaction between institutes and organizations (participants): institutes define "rules of the game"; and organizations act as "players". New institutions emerge when new profit opportunities or other opportunities (social, environmental, etc.) arise that cannot be obtained in an existing institutional environment (system).

A new step in the concept of national innovation systems is to use an evolutionary approach to analyze economic processes. In the framework of this approach, it formulated the concept of "innovative ecosystem", which takes into account expert conclusions about the need to create original innovative ecosystems and a departure from the conventional approach, which is to reproduce previously implemented successful initiatives.

It should be noted that a feature of RAND Corporation's forecast for the development of 16 promising areas of technology development is the consideration of the interrelation of market, socio-economic and technical factors of the development and spread of technology in global markets (RAND, 2006).

Forming, around the production, of an economic linkage system, as an ecosystem, creates the conditions for efficient technology transfer, because today the most promising technological solutions are born only in these conditions. The availability of production to test and implement ideas is an important factor in innovative development, because in dynamic conditions, the time required to transform an idea into a product must be minimal.

\section{Conclusion}

1. The performed analysis of modern theoretical approaches to the analysis of the development of high technologies has shown the lack of systematic approaches to the analysis of this process. Using the principles of systemic approach has made it possible to consider international technology transfer as a channel of interaction between global and national innovation systems. It is determined that the global innovation system within the new framework will be characterized by a high level of internationalization of innovations and convergence of technologies.

2. It is determined that for the high-tech industries, internationalization of the transfer provides for the formation of additional competitive advantages in order to avoid the effect of blocking by expanding the exchange of explicit and implicit knowledge. This effect is due to the fact that each subject of the innovation system is the result of the functioning of a particular innovation ecosystem and has its own knowledge base, possesses certain technologies, is characterized by the social, cognitive and institutional closeness of its participants, which ensures the absorption of knowledge and the generation of innovations of a certain type.

3. The results of the study of high-tech transfer features have analyzed the channels of international transfer and determined that the most effective in terms of transferring 
existing knowledge and criteria of transfer potential is international innovation and technological cooperation.

4. In the course of research of modern domestic and foreign approaches to the management of innovation activity it is determined that the development of high technologies is a systematic process, which is accompanied by significant costs and changes in the innovation system at different levels. On this basis, a classification of the effects of international transfer of high technologies is proposed, which will allow to evaluate its potential for the national economy most fully.

5. The main feature of the global innovation system development is the availability of infrasystems that connect all sectors of the economy into a single technological chain based on interconnections.

6. The results of the international technology transfer should be evaluated on the basis of the technologies' characteristics compared to those available in the host country and the level of the technology's potential realization within the host innovation system. Taking into account the international criterion, together with the differentiation of priorities within the framework of the innovation modernization strategy, allows making efficient use of available resources and competitive advantages in combination with the use of foreign technologies.

7. The factor of the formation of competitive innovative systems is creation of unique innovative environment on the basis of the combination of technological basis, innovative economy and socio-cultural system.

\section{References:}

Achkasova, T.A., \& Gorkin, A.P. (n.d.). Geography of the innovation process stages. URL: http://www.geogr.msu.ru/science/conf/lom/achkasova.php?print=Y.

Antoniuk, L.L., Poruchnik, A.M., \& Savchuk, V.S. (2003) Innovations: Theory, Mechanism of Dissemination and Commercialization: monograph, $394 \mathrm{p}$.

Benko, M., Schrogl, K.-U. (2005). Space Law: Current Problems and Perspectives for Future Regulations. Eleven International Publishing, 176-177.

Biloshkurska, N., Harnyk, O., Biloshkurskyi, M., Liannoi, M., Kudrina, O., \& Omelyanenko, V. (2019). Methodological bases of innovation development priorities integrated assessment International Journal of Civil Engineering and Technology, vol. 10 (1), pp. 1231-1240.

Clean coal mining and processing technologies: Strengthening commercial and political incentives for OECD industrial adoption (2010). IEA, 59 p. URL: www.iea.org/papers/2008/clean_coal_rus.pdf.

European Landmark in nanobiotechnology. Nano2life. (2014). URL: htpp://www.nano2life.org/download/major_achievements.pdf.

Filipenko, A. (2013). Methodological discourse of international economic policy. International economic policy, issue 1, pp. 5-23.

Fisher, J. (2003). Technology Shocks Matter. Federal Reserve Bank of Chicago.

Global Innovation Index (2013). Geneva, WIPO. PR/2013/743. URL: http://www.wipo.int/pressroom/ru/articles/2013/article_0016.html.

Glushak, N.V. (2011). Analysis of the prospects of national technological platforms in the field of high technologies from the standpoint of NBIC convergence. Creative Economy, No. 1 (49), pp. 3-9.

Kondratiev, N.D. (2002). Big business cycles and foresight theory. M .: Economics.

Krasnonosova, O.M., \& Oliinyk, A.D. (2011) Models of state management of scientific, technical and innovative development in the countries of the world. Economical Spaces. Zbirnik of science prats, vol 50, pp. 11-21.

Managing National Systems of Innovation, OECD (1999). 
Omelyanenko, V., \& Kudrina, O. (2018). Research framework for system security of technological and innovation systems. Baltic Journal of Economic Studies, Vol. 4 N. 1, pp. 248-254.

Omelyanenko, V., \& Volodin, D. (2017). Nanoinformatics application framework for R\&D and industrial analisys. 2017 IEEE 7th International Conference Nanomaterials: Application \& Properties, pp. 01NNPT03-1-01NNPT03-4, 2017. https://doi.org/10.1109/NAP.2017.8190183

Polterovich, V. (2008). Principles of forming a national innovation system. Problems of the theory and practice of management, No. 11, pp. 8-19.

Prigulnyi, A.G. (2010). Internationalization of innovation processes: global regulation and leveling of risks. Scientific-analytical journal "Vestnik Sankt-Peterburgskogo universiteta Gosudarstvennoy protivopozharnoy sluzhby MCHS Rossii", No2, pp. 32-37.

Prokopenko, O., Kudrina, O., \& Omelyanenko, V. (2018). Analysis of ICT Application in Technology Transfer Management within Industry 4.0 Conditions (Education Based Approach). CEUR Workshop Proceedings. Vol-2105. pp. 258-273.

Prokopenko, O., Omelyanenko, V., Ponomarenko, T., \& Olshanska, O. (2019). Innovation networks effects simulation models. Periodicals of Engineering and Natural Sciences, 7 (2), pp. 752-762.

RAND Global Technology revolution 2020, RAND (2006).

Rebelo, S. (2010). Models of real business cycles: past, present and future. Issues of Economics, No. 10, pp. $56-67$.

The world at the turn of the millennium (forecast for the development of the global economy up to 2015). M .: "Izdatel'skiy Dom Novyy Vek", (2001), 592 p.

Towards a European Strategy for Nanotechnology. European Commission. Communication, Brussels. (2004). URL: http://ec.europa.eu/research/industrial_technologies/pdf/ nanotechnology_communication_en.pdf

Vernon, R. (1966). International investment and international trade in the product cycle. Quarterly Journal of Economics, Vol. 80, pp. 190-207. 